\title{
A Methodology for Characterization of the Strain Rate-Dependent Behavior of PU Foam
}

\author{
N. Shivakumar and Anindya Deb \\ Indian Institute of Science \\ Clifford Chou
}

H. Chittappa

Uvce

\begin{abstract}
Polymeric foams are known to be sensitive to strain rate under dynamic loads. Mechanical characterization of such materials would not thus be complete without capturing the effect of strain rate on their stress-strain behaviors. Consistent data on the dynamic behavior of foam is also necessary for designing energy-absorbing countermeasures based on foam such as for vehicle occupant safety protection. Strain rates of the order of 100-500 s-1 are quite common in such design applications; strain rates of this range cannot be obtained with an ordinary UTM (universal testing machine) and a special test set-up is usually needed. In the current study, a unique approach has been suggested according to which quasi-static tests at low strain rates and low velocity drop tests at medium strain rates are utilized to arrive at an empirical relation between initial peak stress and logarithm of strain rate for a rigid closed-cell PU foam. Using a stress-scaling methodology and the empirical relation mentioned, foam stress-strain curves are obtained for a number of strain rates spanning low (from $0.00033 \mathrm{~s}^{-1}$ ) to high strain rates (up to $1000 \mathrm{~s}^{-1}$ ). This data on foam material behavior is expected to be particularly useful in numerical modelling of foam-based countermeasures for impact energy absorption applications.
\end{abstract}

CITATION: Shivakumar, N., Deb, A., Chou, C., and Chittappa, H., "A Methodology for Characterization of the Strain RateDependent Behavior of PU Foam," SAE Int. J. Mater. Manf. 7(3):2014, doi:10.4271/2014-01-0539.

\section{INTRODUCTION}

Dynamic characterization of foam i.e. finding stress-strain responses at strain rates higher than quasi-static is essential for predicting its behavior in many real-world applications such as energy-absorption under impact loads. However, generating stress-strain data at dynamic strain rates is often a challenging task due to the necessity of specialized equipment such as a Split Hopkinson Pressure Bar [1, 2, $\underline{3}$ ] which can be expensive and not ordinarily available in an engineering laboratory. This device, despite perhaps being the best resource for ascertaining material behavior at high strain rates, has limitations due to its indirect nature arising from reliance on one-dimensional wave theory for solids, difficulty in performing tensile tests, special material requirements for incident and transmission bars for testing of soft materials such as foam and fibre-reinforced composites, etc. Additionally, the SHPB is generally suitable for strain rates of the order of $1000 \mathrm{~s}^{-1}$ or higher [4] although SHPB tests on polymeric foams with acrylic bars have been reported for strain rates in the range of $500-2500 \mathrm{~s}^{-1}[$ ].
Due to the relevance of rigid PU foam for impact safety and packaging applications, attention is paid here toward developing a simple methodology for determining the stressstrain responses of a rigid PU foam at low to medium strain rates. However, it may be pointed out that the methodology adopted is not dependent on the type of foam being considered and can be applied to cellular materials in general. A review of relevant literature indicates that a number of investigators have studied the behavior of polymeric foam under impact loading conditions although desired stress-strain behaviors could not in general be obtained as strain rate does not remain constant in such tests. In fact, in an impact test, strain rate will vary from a maximum value at the instant of impact to zero when the impactor comes to a stop. It is noted that Ouellet, Cronin and Worswick [5] have presented stress-strain curves for polymeric foams directly from impact tests; however, the authors have observed that such data is likely to be inaccurate due to varying strain rate in an impact test. It may be mentioned that a number of investigators have studied the behavior of polymeric foam experimentally under impact loads and carried out numerical simulation to predict the responses and deformation. The influence of strain rate on the mechanical response of 
foams was shown in drop-weight []] and impact sled experiments [7] and was found to be crucial in defining energy absorbing ability. Zhang et al. [8] investigated the impact response of polymer foams using a pneumatically driven impact machine. Kipp et al. []ㅡ conducted studies under high-speed impact conditions. Polyurethane foams have found wide applications in recent automobile bumper designs for impact energy absorption, under vehicle interior trim as occupant impact safety countermeasures, and in shockisolating encapsulation [10]. Lankford and Dannemann [11] used a drop-weight tower to investigate the dynamic response of elastomeric polymer foams and found their stress-strain behavior to be rate dependent. Progelhof [12] conducted dynamic tests in industry to characterize the impact energy absorption behavior of rigid polymer foams using a drop-weight tower. Faruque, Liu and Chou [13] formulated a strain ratedependent constitutive model and implemented in an explicit dynamic finite element code developed at Ford Research Laboratory. Chou et al. [14] tested polyurethane foams of varying density under uniaxial compressive loading condition at different rates and temperatures.

As mentioned earlier and revealed through the survey of a cross-section of relevant literature ([14], [15], [16], [17], [18], [19], [20], [21]), methods exist for the determination of stressstrain responses of foam at medium to high strain rates. However, the method discussed here according to which UTM-based tests at low strain rates are supplemented with drop-weight impact tests and a scaling technique has not been reported earlier. In the current study, UTM-based compression tests on cubical samples of a rigid PU foam of a given density (viz. $0.42 \mathrm{gm} / \mathrm{cc}$ ) and desired mixing ratio of $1: 1.1$ by volume of polyol:isocyanate are carried out at various low strain rates (by varying cross-head speed). These are then followed up with drop tests on similar specimens in a Versatile Test Rig (named so because of its capability for different types of impact tests). An empirical relation is developed for predicting the initial peak stress of foam using results from low (UTM-based) and medium (corresponding to drop tests) strain rates. A strategy is adopted for developing stress-strain curves at low to medium strain rates with the quasi-static response at a cross-head speed of $1 \mathrm{~mm} / \mathrm{min}$ as a baseline and applying a scaling approach as explained in the ensuing sections.

\section{LOW STRAIN RATE TESTS}

In order to bring out the effect of strain rate on mechanical response of the rigid PU foam under consideration at low strain rates, tests were conducted using a standard servo-hydraulic UTM. Cubical specimens (of size $50 \times 50 \times 50 \mathrm{~mm}^{3}$ ) were compressed between compression platens at different loading rates such as $1 \mathrm{~mm} / \mathrm{min}, 50 \mathrm{~mm} / \mathrm{min}$, and $300 \mathrm{~mm} / \mathrm{min}$, resulting in the global strain rates of $3.33 \times 10^{-4} \mathrm{~s}^{-1}, 1.67 \times 10^{-2}$ $\mathrm{s}^{-1}$ and $0.1 \mathrm{~s}^{-1}$ respectively which can be considered as low strain rates. It is noted that strain rate $(\dot{\varepsilon})$ is calculated from the relation $\frac{v}{h_{\mathrm{o}}}$, in which $v$ is the instantaneous cross-head speed (maintained as constant in a UTM-based test) and $h_{0}$ is the original height of a foam specimen. In these compression tests, the specimens were compressed up to $70 \%$ of their original height (i.e. by $35 \mathrm{~mm}$ ). Experimental engineering stress-strain behaviors of the foam for the three cross-head speeds or equivalently constant strain rates mentioned are shown in Figure 1.

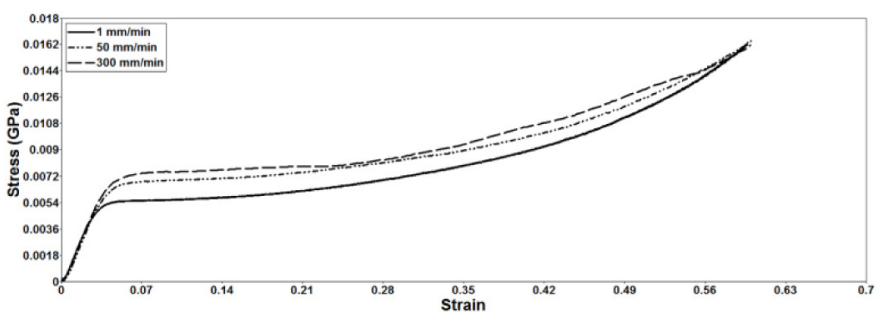

Figure 1. Stress-strain behaviors of foam at different constant cross-head speeds

\section{IMPACT TESTS}

A Versatile Test Rig consisting of a gravity accelerated and steel rod guided variable mass impactor, is used for impact testing of foam specimens. The test rig is shown in Figure 2. The impactor mass can be varied from $14 \mathrm{~kg}$ to $50 \mathrm{~kg}$ in steps of $5 \mathrm{~kg}$, while impact velocity can be varied by changing the drop-height. Impact loads in the rig are captured using a $50 \mathrm{kN}$ piezoelectric load cell, which is mounted on the impactor between its head and body through a high speed data acquisition system. The data acquisition system used for capturing the load-cell signals consists of a National Instruments make PCl-6220 data acquisition card installed in an Intel® Core ${ }^{\text {TM }}$ i7 PC with Windows 7 operating system and a custom-coded LABVIEW-based user interface for operation and data gathering.

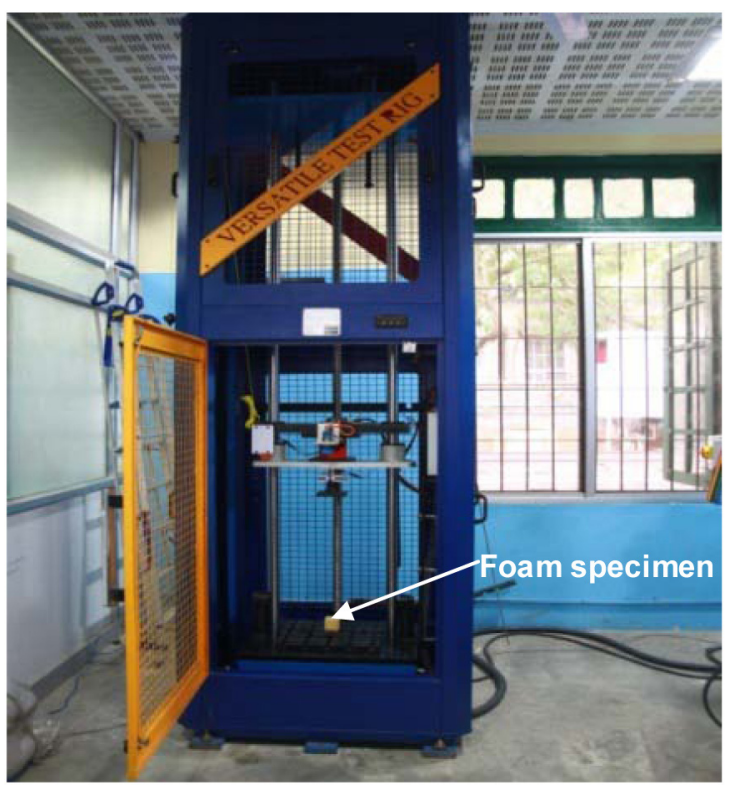

Figure 2. Impact testing machine with foam specimen placed on the base plate 
One of the parameters of interest in an impact test is the velocity of the impactor at the moment of impact. There can be several ways of estimating this velocity, such as, (i) energy method or using Newton's second law of motion, (ii) processing of images obtained using a high speed camera (HSC), (iii) measurement using an optical velocity trap such as two laser beams separated by a small distance which are successively interrupted by the impactor before hitting a test specimen, and (iv) integration of deceleration-time history obtained from load cell response. Method (i) yields the ideal impact velocity which has been found to be slightly higher as compared to that obtained using HSC images i.e. Method (ii); the reduction in impact velocity as compared to the ideal (i.e. $\sqrt{\mathbf{2} \mathbf{g h}}$, where, $\mathbf{g}$ = acceleration due to gravity, and $\mathbf{h}=$ impactor drop-height) is due to frictional resistance between the impactor and guiderods. For verification of impact velocity, a High Speed Camera of make IDT/Redlake and model MotionPro YL-4, with capabilities of 4000 fps @ $1024 \times 1024$ (full resolution), was used to capture the drop velocity and deformation pattern of PU foam. The Versatile Test Rig is equipped with an optical velocity trap mentioned in Method (iii), however, it can be considered as yielding an average velocity only. Method (iv), truly speaking, yields the change in velocity which is equal to the integral of acceleration response during an impact event (i.e. $\int_{0}^{T}-\frac{\mathrm{F}(\mathrm{t})}{\mathrm{m}} d t$, where $\mathbf{F}(\mathbf{t})=$ impact force recorded at any time $\mathrm{t}$ using load cell and high speed data acquisition system, $\mathbf{m}=$ mass of impactor, and $\mathbf{T}=$ time at the end of impact event); however, the change in velocity would be equal to the initial impact velocity only if the impactor during a test comes to rest (i.e. final velocity of the impactor is zero) after complete absorption of impact kinetic energy by a test specimen.

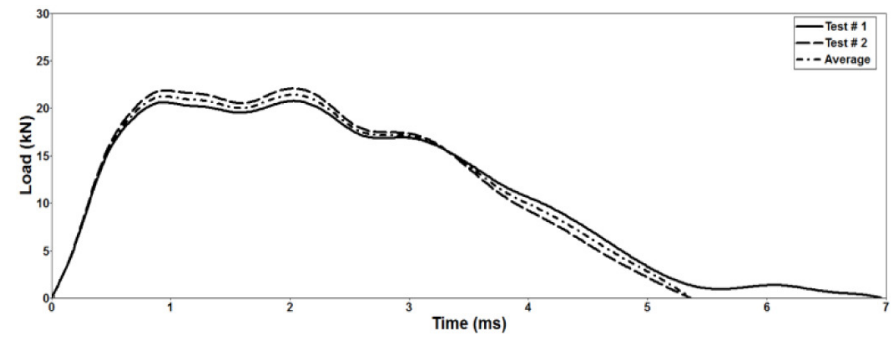

Figure 3. Recorded load-time histories for an impactor drop-height of $1 \mathrm{~m}$

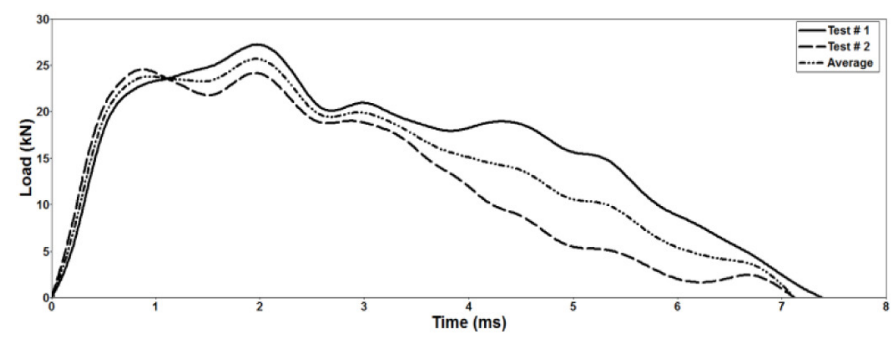

Figure 4. Recorded load-time histories for an impactor drop-height of $1.5 \mathrm{~m}$
Polyurethane foam samples of size $50 \times 50 \times 50 \mathrm{~mm}^{3}$ and a given density (i.e. $0.42 \mathrm{gm} / \mathrm{cc}$ approximately) were tested for two impactor drop-heights of $1 \mathrm{~m}$ and $1.5 \mathrm{~m}$. The mass of the impactor for these tests was kept fixed at $14 \mathrm{~kg}$. Two tests are performed for each height and the dynamic responses were found to be repetitive. Pairs of recorded responses for $1 \mathrm{~m}$ and $1.5 \mathrm{~m}$ drop-heights resulting into nominal impact velocities of $4.4 \mathrm{~m} / \mathrm{s}$ and $5.4 \mathrm{~m} / \mathrm{s}$ respectively are shown in Figures 3 and $\underline{4}$ along with the average responses. A comparison of the average responses from Figures 3 and $\underline{4}$ for $1 \mathrm{~m}$ and $1.5 \mathrm{~m}$ drop-heights is given in Figure 5 . It is seen in the latter figure that the initial peak load is higher for a drop-height of $1.5 \mathrm{~m}$ as compared to that of $1 \mathrm{~m}$ which is likely to be due to the effect of increased peak strain rate in the former case.

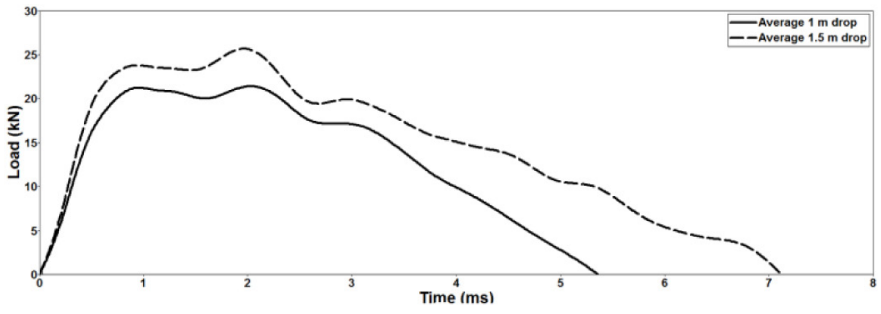

Figure 5. Average load-time curves for impactor drop-heights of $1 \mathrm{~m}$ and $1.5 \mathrm{~m}$

It is noted that the peak strain rates for the drop-weight impact tests described above can be estimated as $88 \mathrm{~s}^{-1}$ and $108 \mathrm{~s}^{-1}$ for the respective impact velocities of $4.4 \mathrm{~m} / \mathrm{s}$ and $5.4 \mathrm{~m} / \mathrm{s}$ $\underline{\mathbf{v}_{\mathbf{i}}}$

using the expression $\frac{\mathbf{h}_{0}}{\mathbf{h}_{0}}$, where $\mathbf{v}_{\mathbf{i}}$ is the impact velocity and $\mathbf{h}_{\mathbf{0}}$ is the initial height of a foam specimen i.e. $50 \mathrm{~mm}$.

\section{CAPTURING THE EFFECT OF STRAIN RATE ON INITIAL PEAK STRESS}

The stress-strain results obtained for low strain rates in the UTM-based tests were essentially at constant strain rates as the cross-head velocity could be maintained at a fixed level in such tests. On the other hand, the strain rate continuously changed in the impact tests dropping from a peak value at the time of initial impact to zero as the impactor came to a stop at the end of a test. Hence, results from drop tests cannot be directly used for obtaining stress-strain curves at average strain rates which are otherwise higher than what a common UTM would permit. It is observed that, at the time of reaching the initial peak load (at the end of what may be regarded as the linear elastic phase) in an impact test, the strain rate would be close to the peak value. An empirical relation can therefore be derived for predicting initial peak stress as a function of strain rate using the information given in Table 1 from the three UTM-based tests at low strain rates reported earlier and the two drop-weight impact tests with peak strain rates which can be considered to be in the medium strain rate range. It is pointed out that the initial peak stress is obtained by dividing the initial peak load (at the onset of plastic flow behavior) by foam cross-sectional area. As strain rate varied in a large range in the tests considered, it would be prudent to derive a 
regression relation between initial peak stress and the logarithm of strain rate for the purpose of interpolation and extrapolation to high strain rates.

Table 1. Initial peak stress of foam obtained from UTM-based and impact tests

\begin{tabular}{|c|c|c|c|c|c|}
\hline $\begin{array}{c}\text { Type of } \\
\text { test } \\
\text { head / } \\
\text { impact } \\
\text { velocity } \\
\text { (m/s) }\end{array}$ & $\begin{array}{c}\text { Strain } \\
\text { rate } \\
\left(\mathbf{s}^{-1}\right)\end{array}$ & $\begin{array}{c}\text { Cross- } \\
\text { (Strain } \\
\text { rate) }\end{array}$ & $\begin{array}{c}\text { Peak } \\
\text { load } \\
\text { (kN) }\end{array}$ & $\begin{array}{c}\text { Initial } \\
\text { peak } \\
\text { stress } \\
\text { (MPa) }\end{array}$ \\
\hline $\begin{array}{c}\text { UTM @ } \\
1\end{array}$ & 0.016 & $\begin{array}{c}0.0003 \\
\text { mm/min }\end{array}$ & -3.48 & 13.5 & 5.4 \\
\hline $\begin{array}{c}\text { UTM @ } \\
50\end{array}$ \\
$\begin{array}{c}\text { mm/min } \\
\text { UTM @ } \\
\begin{array}{c}300 \\
\text { mm/min }\end{array}\end{array}$ & 0.833 & 0.0167 & -1.78 & 16.5 & 6.6 \\
\hline $\begin{array}{c}\text { Impact } \\
\text { @ 1 m } \\
\text { drop- } \\
\text { height }\end{array}$ & 4.4 & 0.1 & -1 & 17.5 & 7 \\
\hline $\begin{array}{c}\text { Impact } \\
\text { @ 1.5 m } \\
\text { drop- } \\
\text { height }\end{array}$ & 5.4 & 108 & 2.03 & 23 & 9 \\
\hline
\end{tabular}

\section{ESTIMATION OF STRESS-STRAIN CURVES FOR A RANGE OF STRAIN RATES}

Initial peak stress against log of strain rate from Table 1 is plotted in Figure 6. Eq. (1) is obtained as a best-fit linear relation between the dependent variable i.e. initial peak stress and independent variable i.e. logarithm of strain rate to the base 10 with a high value of goodness of fit $\left(R^{2}=0.933\right)$.

$$
y=0.551 x+7.452
$$

where:

$\boldsymbol{y}=$ initial peak stress in $\mathrm{MPa}$

$\boldsymbol{x}=\log _{10}\left(\right.$ strain rate in $\left.\mathrm{s}^{-1}\right)$

Using Eq. (1), initial peak stress is calculated for a number of strain rates beginning with the lower strain rates earlier considered (except the lowest strain rate of $0.00033 \mathrm{~s}^{-1}$ ) and higher strain rates in multiples of 10 up to $1000 \mathrm{~s}^{-1}$. These values of peak stress are given in Table 2 . For most applications pertaining to crashworthiness of vehicles and packaging, the maximum strain rate is expected to be within this range. Also, the extrapolation of peak initial stress to very high strain rates may not be valid as the experimental results used for deriving Eq. (1) were limited to a maximum strain rate of $108 \mathrm{~s}^{-1}$.

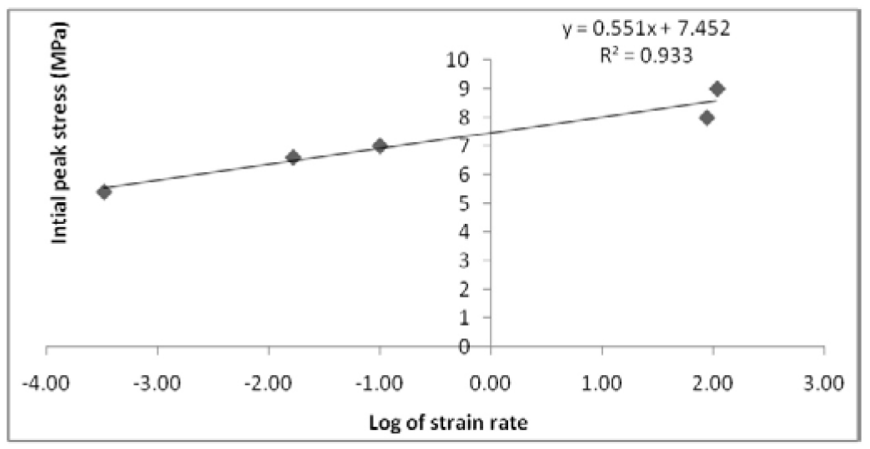

Figure 6. Initial peak stress versus strain rate on semi-log scale

Table 2. Predicted initial peak stress for a given strain rate obtained from Eq. (1)

\begin{tabular}{|c|c|}
\hline $\begin{array}{c}\text { Strain-rate } \\
\left(\mathbf{s}^{-1}\right)\end{array}$ & Initial peak stress $\mathbf{( M P a )}$ \\
\hline 0.0167 & 6.47 \\
\hline 0.1 & 6.90 \\
\hline 10 & 8.00 \\
\hline 100 & 8.56 \\
\hline 1000 & 9.11 \\
\hline
\end{tabular}

According to the present proposed methodology, the stressstrain responses for higher strain rates are obtained by scaling up the stress-strain curve for the lowest value of strain rate i.e. $0.00033 \mathrm{~s}^{-1}$ (in Table 1) which can be treated as a quasi-static case. The approach is demonstrated below for a strain rate of $10 \mathrm{~s}^{-1}$.

Initial peak stress for a strain rate of $0.00033 \mathrm{~s}^{-1}=5.4 \mathrm{MPa}$ (from Table 1)

Initial peak stress for a strain rate of $10 \mathrm{~s}^{-1}=8 \mathrm{MPa}$ (from Table 2)

Thus, scale factor $=8 / 5.4=1.44$

The values of stress in the discrete representation of the stress-strain curve for a strain rate of $0.00033 \mathrm{~s}^{-1}$ are multiplied with the above scale factor to obtain the approximate stressstrain curve for a strain rate of $10 \mathrm{~s}^{-1}$.

Table 3. Scale factors for different strain rates

\begin{tabular}{|c|c|}
\hline $\begin{array}{c}\text { Strain-rate } \\
\left(\mathbf{s}^{-1} \mathbf{)}\right.\end{array}$ & Scale factor \\
\hline 0.00033 & 1.00 \\
\hline 0.0167 & 1.17 \\
\hline 0.1 & 1.25 \\
\hline 10 & 1.44 \\
\hline 100 & 1.54 \\
\hline 1000 & 1.64 \\
\hline
\end{tabular}

Using the above approach, scale factors are obtained for a number of other strain rates and are listed in Table 3 . Stressstrain curves derived this way for all strain rates given in Table $\underline{3}$ along with the baseline experimental curve for the lowest 
strain rate of $0.00033 \mathrm{~s}^{-1}$ are presented in Figure 7. Stressstrain curves at high strain rates for polymeric foams tend to be smooth as reported by Ouellet, Cronin and Worswick [ $]$ ]; also, the shapes of these curves are essentially similar to those at low strain rates. The present approach of deriving stress-strain behaviors at medium to high strain rates by appropriately scaling up the quasi-static stress-strain curve can therefore be regarded as justifiable. Additionally, even if oscillations exist in stress-strain curves as obtained by some investigators, it is advisable to use smoothened versions of such curves for numerical simulation [22] which is really the intent behind deriving the stress-strain curves at various strain rates in the present study. It is noted that the stress-strain curves obtained here can be of valuable aid in numerically predicting the behavior of foam-based countermeasures for impact safety protection using explicit nonlinear finite analysis tools such as LS-DYNA in appropriate constitutive models.

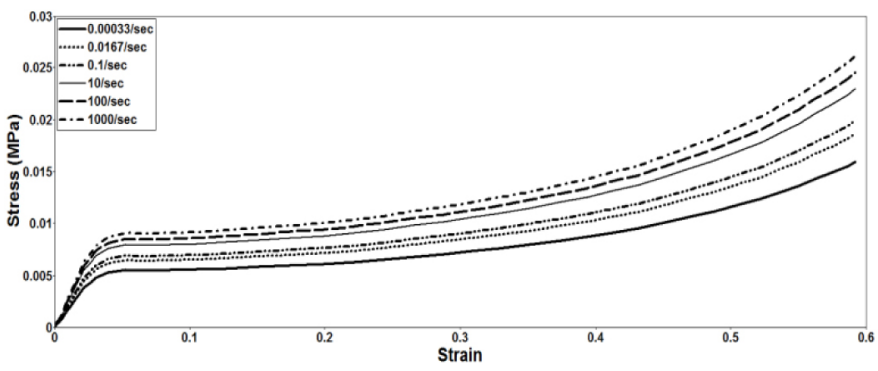

Figure 7. Stress-strain curves for low to high strain rates for a given crushable PU foam based on the current approach

\section{CONCLUSIONS}

A detailed study on the effect of strain rate on the mechanical behavior of a rigid PU foam under compressive loading has been carried out here. A simple although approximate approach has been devised according to which quasi-static tests at low strain rates and low velocity drop tests at medium strain rates are utilized combined with a stress scaling methodology to arrive at foam stress-strain curves for a number of strain rates spanning low (from $0.00033 \mathrm{~s}^{-1}$ ) to high strain rates (up to1000 s-1). The motivation behind the present work has been to circumvent the use of SHPB which is not a commonly available facility and yet capture the effect of strain rate on foam compressive strength so that more realistic simulation of the behavior of foam under impact loading can be carried out as compared to completely ignoring the effect of strain rate.

\section{REFERENCES}

1. Shim J, Mohr D. Using split Hopkinson pressure bars to perform large strain compression tests on polyurea at low, intermediate and high strain rates. International Journal of Impact Engineering; 36 (2009): 1116-1127.

2. Songa B, Chena WW, Doua S, Nancy A. Winfree NA, Kang JH. Strain-rate effects on elastic and early cell-collapse responses of a polystyrene foam. International Journal of Impact Engineering; 31 (2005): 509-521.

3. Subhasha G, Liu Q, Gao XL. Quasistatic and high strain rate uniaxial compressive response of polymeric structural foams. International Journal of Impact Engineering; 32 (2006): 1113-1126.
4. Field JE, Walley SM, Proud WG, Goldrein HT, Siviour CR. Review of experimental techniques for high rate deformation and shock studies. International Journal of Impact Engineering; 30 (2004): 725-775.

5. Ouellet S, Cronin D, Worswick M. Compressive response of polymeric foams under quasi-static, medium and high strain rate conditions. Polymer Testing; 25 (2006) 731-743.

6. Progelhof RC. Impact measurement of low-pressure thermoplastic structural foam. In: Kessler SL, Adams GC, Driscoll SB, Ireland DR, Editors. Proceedings of Instrumented Impact Testing of Plastics and Composite Materials, Houston (TX): ASTM STP 936; 1986: 105-116.

7. Sounik DF, Gansen P. Clemons JL, Liddle JW. Head-impact testing of polyurethane energy-absorbing (EA) foams. Journal of Materials and Manufacturing 1997; 106(5):211-220.

8. Zhang J, Kikuchi N, Li V, Yee A, Nusholtz G. Constitutive modeling of polymeric foam material subjected to dynamic crash loading. International Journal of Impact Engineering 1998; 21 (5): 369-386.

9. Kipp ME, Chhabildas LC, Reinhart WD, and Wong MK. Polyurethane foam impact experiments and simulations. APS Shock Compression of Condensed Matter--1999, June 27-July 2, Snowbird, UT, APS 1999.

10. Schumachel W. Polyurethane foams to improve shock absorption and assembly of new bumper systems. Proceedings of Polyurethanes World Congress 1987:50 Years of Polyurethanes, Aachen, Germany, Sept. 29-Oct. 2, Technomic Publishing Company, 248-251 1987.

11. Lankford J, Dannemann KA. Strain rate effects in porous materials. In: Schwartz DS, Shih DS, Evans AG, Wadley HNG, Editors. Porous and Cellular Materials for Structural Applications; Warrendale, PA: Materials Research Society; 1998: 103-108.

12. Progelhof RC. Impact measurement of low-pressure thermoplastic structural foam. In: Kessler SL, Adams GC, Driscoll SB, Ireland DR, Editors. Proceedings of Instrumented Impact Testing of Plastics and Composite Materials. Houston (TX): ASTM STP 936; 1986: 105-116.

13. Faruque, O., Liu, N., and Chou, C., "Strain Rate Dependent Foam - Constituitive Modeling and Applications," SAE Technical Paper 971076, 1997, doi:10.4271/971076.

14. Chou CC, Zhao Y, Chai L, Co J, Lim GG and Lin TC. Development of foam models using LS-DYNA3D. The Second International LS-DYNA3D Users' Conference held in San Francisco, California, September 20-21, 1994. Paper No. 2IL- SD3D125.

15. Chou, C., Zhao, Y., Lim, G., Patel, R. et al., "Comparative Analysis of Different Energy Absorbing Materials for Interior Head Impact," SAE Technical Paper 950332, 1995, doi:10.4271/950332.

16. Chou, C., Zhao, Y., Chai, L., Co, J. et al., "Development of Foam Models as Applications to Vehicle Interior," SAE Technical Paper 952733, 1995, doi:10.4271/952733.

17. Chou CC, Zhao Y, Lim GG and Patel RN. Testing, analysis and finite element modeling of polyurethane foams. Progress in Advanced Materials and Mechanics, Proceedings of the international conference on advanced materials. August 12-15, Beijing, China, 471-476, 1996.

18. Faruque, M., Dhulipala, S., and Chou, C., "Characterization of Foam Under Impact Loading," SAE Technical Paper 960156, 1996 doi:10.4271/960156.

19. Chou CC, Liu N, Zhao Y, Wu CC, Patel RN and Walker LA. Testing, analysis and finite element modeling of polyurethane foams for upper vehicle interior applications. Proceedings of Automotive Body Interior and Safety Systems, Vol. 23, Ed. by Kelker S. G. Szefi R. J. and Roessler D., International Body Engineering Conference, October 1-3, 1996.

20. Faruque MO, Liu N and Chou CC. Energy absorbing foam constitutive modeling and application. 1996 ASME Winter Annual Meeting, Atlanta, Georgia, Nov. 18-22, Nov. 1996. Crashworthiness and Occupant Protection in Transportation Systems, AMD-Vol 218, pp. 151-160, Nov. 1996.

21. Chou, C., Zhao, Y., Lim, G., and Song, G., "A Constitutive Model for Polyurethane Foams with Strain-Rate and Temperature Effects," SAE Technical Paper 980967, 1998, doi:10.4271/980967.

22. Du Bois PA, Kolling S, Koestersc M, Frank T. Material behaviour of polymers under impact loading. International Journal of Impact Engineering; 32 (2006): 725-740. 


\section{CONTACT INFORMATION}

Prof. Anindya Deb

Centre for Product Design and Manufacturing

Indian Institute of Science, Bangalore, India

adeb@.cpdm.iisc.ernet.in

All rights reserved. No part of this publication may be reproduced, stored in a retrieval system, or transmitted, in any form or by any means, electronic, mechanical photocopying, recording, or otherwise, without the prior written permission of SAE International.

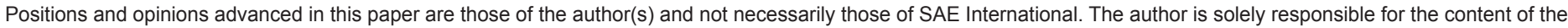
paper. 